NBER WORKING PAPER SERIES

A 'RECIPROCAL DUMPING' MODEL

OF INTERNATIONAL TRADE

James A. Brander

Paul Krugman

Working Paper No. 1194

NATIONAL BUREAU OF ECONOMIC RESEARCH

1050 Massachusetts Avenue

Cambridge, MA 02138

August 1983

The research reported here is part of the NBER's research program in International Studies and program in Productivity (World Economy). Any opinions expressed are those of the authors and not those of the National Bureau of Economic Research. 


\section{A 'Reciprocal Dumping' Model of International Trade}

\section{ABSTRACT}

This paper develops a model in which the rivalry of oligopolistic firms serves as an independent cause of international trade. The model shows how such rivalry naturally gives rise to "dumping" of output in foreign markets, and shows that such dumping can be "reciprocal" -- that is, there may be two-way trade in the same product. Reciprocal dumping is shown to be possible for fairly general specification of firm behaviour. The welfare effects of this seemingly pointless trade are ambiguous. On one hand, resources are wasted in the cross-handling of goods; on the other hand, increased competition reduces monopoly distortions. Surprisingly, in the case of free entry and Cournot behaviour reciprocal dumping is unambiguously beneficial.

\author{
James A. Brander \\ Department of Economics \\ University of British \\ Columbia \\ Vancouver, British Columbia \\ V6T 1 Y2 Canada
}

Paul Krugman

Sloan School of Management

Massachusetts Institute of Technology 50 Memorial Drive

Cambridge, MA 02139 


\section{A 'Reciprocal Dumping' Model of International Trade James Brander and Paul Krugman}

The phenomenon of "dumping" in international trade can be explained by the standard theory of monopolistic price discrimination. ${ }^{1}$ If a profit maximizing firm believes it faces a higher elasticity of demand abroad than at home, and it is able to discriminate between foreign and domestic markets, then it will charge a lower price abroad than at home. Such an explanation seems to rely on "accidental" differences in country demands. In this paper, however, we show how dumping arises for systematic reasons associated with oligopolistic behaviour.

Brander (1981) develops a model in which the rivalry of oligopolistic firms serves as an independent cause of international trade and leads to two-way trade in identical products. ${ }^{2}$ In this paper we build on Brander (1981) to argue that the oligopolistic rivalry between firms naturally gives rise to "reciprocal dumping": each firm dumps into other firms' home markets.

We generalize Brander (1981) in that reciprocal dumping is shown to be robust to fairly general specification of firms' behaviour and market demand. The crucial element is what Helpman (1982) refers to as a 'segmented markets' perception: each firm perceives each country as a separate market and makes distinct quantity decisions for each.

Reciprocal dumping is rather striking in that there is pure waste in the form of unnecessary transport costs. ${ }^{3}$ Without free entry, welfare may improve as trade opens up and reciprocal dumping occurs, but it is also possible that welfare may decline. One wonders, therefore, if such a model might not provide a rationale for trade restirction. With free entry, the contrary seems to be true. We derive the fairly strong result that with 
free entry both before and after trade, the opening of trade (and the resultant reciprocal dumping is definitely welfare improving for the Cournot case. The procompetitive effect of having more firms and a larger overall market dominates the loss due to transport costs in this second best imperfectly competitive world.

Section 2 develops a simple model of Cournot duopoly and trade which shows how reciprocal dumping can occur, and presents the associated welfare analysis. Section 3 describes the free entry zero profit equilibrium and derives the result the trade is welfare-improving in this case. Section 4 contains concluding remarks.

\section{The Basic Model}

Assume there are two identical countries, one "domestic" and one "foreign"; and that each country has one firm producing commodity $z$. There are transport costs incurred in exporting goods from one country to the other. The main idea is that each firm regards each country as a separate market and therefore chooses the profit-maximizing quantity for each country separately. Each firm has a Cournot perception: it assumes the other firm will hold output fixed in each country.

The domestic firm produces output $x$ for domestic consumption and output $x *$ for foreign consumption. Marginal cost is a constant, $c$, and transport costs of the "iceberg" type imply that the marginal cost of export is $c / g$ where $0 \leq \mathrm{g} \leq 1$. Similarly, the foreign firm produces output $y$ for export to the domestic country and output $y^{*}$ for its own market, and faces a symmetric cost structure. Using $p$ and $\mathrm{p}^{*}$ to denote domestic and foreign price, domestic and foreign profits can be 
written, respectively

$$
\begin{aligned}
\pi & =x p(z)+x^{*} p^{*}\left(Z^{*}\right)-c\left(x+x^{*} / g\right)-F \\
\pi^{*} & =y p(z)+y^{*} p^{*}\left(z^{*}\right)-c\left(y / g+y^{*}\right)-F^{*}
\end{aligned}
$$

where asterisks generally denote variables associated with the foreign country and $F$ denotes fixed costs. A little inspection reveals that the profit-maximizing choice of $\mathrm{x}$ is independent of $\mathrm{x}^{*}$ and similarly for $\mathrm{y}$ and $y^{*}$ : each country can be considered separately. ${ }^{4}$ By symetry we need consider only the domestic country.

Each firm maximizes profit with respect to own output, which yields first order conditions

$$
\begin{aligned}
& \pi_{x}=x p^{\prime}+p-c=0 \\
& \pi_{y}^{*}=y p^{\prime}+p-c / g=0
\end{aligned}
$$

where primes or subscripts denote derivatives. These are "best-reply" functions in implicit form. Their solution is the trade equilibrium. Using the variable $\sigma$ to denote $y / z$, the foreign share in the domestic market, and letting $\varepsilon=-\mathrm{p} / \mathrm{ZP}^{\prime}$, the elasticity of domestic demand, these implicit best-reply functions can be rewritten:

$$
\begin{aligned}
& \mathrm{p}=c \varepsilon /(\varepsilon+\sigma-1) \\
& \mathrm{p}=c \varepsilon / g(\varepsilon-\sigma)
\end{aligned}
$$

Equations $\left(3^{\prime}\right)$ and $\left(4^{\prime}\right)$ are two equations that can be solved for $p$ and $\sigma$. The solutions are

$$
\begin{aligned}
& \mathrm{p}=c \varepsilon(1+g) / g(2 \varepsilon-1) \\
& \sigma=(\varepsilon(g-1)+1) /(1+g)
\end{aligned}
$$


These solutions are an equilibrium only if second order conditions are satisfied:

$$
\pi_{\mathrm{xx}}=\mathrm{xp} "+2 \mathrm{p}^{\prime}<0 ; \quad \pi_{\mathrm{yy}}^{*}=\mathrm{yp}^{\prime \prime}+2 \mathrm{p}^{\prime}<0
$$

We also impose the following conditions

$$
\pi_{\mathrm{xy}}=\mathrm{xp} \mathrm{p}^{\prime \prime}+\mathrm{p}^{\prime}<0 ; \quad \pi_{\mathrm{yx}}^{*}=\mathrm{yp}^{\prime \prime}+\mathrm{p}^{\prime}<0
$$

Conditions ( 8 ) mean that own marginal revenue declines when

the other firm increases its output, which seems a very reasonable requirement. They are equivalent to reaction functions (or best-reply functions) being downward sloping. They imply stability and, if they hold globally, uniqueness of the equilibrium. It is not inconceivable that (8) might be violated by possible demand structures, but such cases would have to be considered unusual. In any case, pathological examples of noncooperative models are well understood (see, for example, Seade (1980) and Friedman (1977)) and we have nothing new to say about such problems here. Accordingly we assume (7) and (8) are satisfied. ${ }^{5}$

Positive solutions to (5) and (6) imply that two-way trade arises in this context. A positive solution will arise if $\varepsilon<1 /(1-g)$ at the equilibrium since this implies that price exceeds the marginal cost of exports $(\mathrm{p}>\mathrm{c} / \mathrm{g})$ and that $\sigma>0$. Subject to this condition, and given ( 7 ) and (8), a unique stable two-way trade equilibrium holds for arbirary demand. (Brander (1981) considered the case of linear demand only.) It can be easily shown $^{6}$ that, at equilibrium, each firm has a smaller market share of its export market than of its domestic market. Therefore, perceived marginal revenue is higher in the export market. The effective marginal cost of delivering an exported unit is higher than for a unit of domestic sales, because of 
transport costs, but this is consistent with the higher marginal revenue. Thus perceived marginal revenue can equal marginal cost in both markets at positive output levels. This is true for firms in both countries which gives rise to two-way trade. Moreover each firm has a smaller markup over cost in its export market than at home: the f.o.b. price for exports is below domestic price: reciprocal dumping.

The case of constant elasticity demand, $\mathrm{p}=\mathrm{AZ}-1 / \varepsilon$, is a useful special case which is illustrated in Figure 1.

\section{FIGURE 1}

For profit-maximization by the domestic firm (condition ( $\left.3^{\prime}\right)$ ), p is decreasing in $\sigma$, while condition ( $\left.4^{\prime}\right)$ for the foreign firm has price increasing in $\sigma$. The intercepts on the price axis are, respectively, $c \varepsilon /(\varepsilon-1)$ and $c / g$ so provided $c \varepsilon /(\varepsilon-1)>c / g($ or $\varepsilon<1 / 1-g)$ ) the intersection must be at a positive foreign market share. This condition has a natural economic interpretation, since $c \varepsilon /(\varepsilon-1)$ is the price which would prevail if there were no trade, while $\mathrm{c} / \mathrm{g}$ is the marginal cost of exports. What the condition says is that reciprocal dumping will occur if monopoly markups in its absence would exceed transport costs.

Clearly the reciprocal dumping solution is not pareto efficient. Some monopoly distortion persists even after trade, and there are socially pointless transportation costs incurred in cross-hauling. What is less clear is whether, given a second best world of imperfect competition, free trade is superior to autarky. This is a question with an uncertain answer, because there are two effects. On one hand, allowing trade in this model leads to waste in transport, tending to reduce welfare. On the other 
hand, international competition leads to lower prices, reducing the monopoly distortion.

If demand is assumed to arise from a utility function that can be approximated by the form $\mathrm{U}=\mathrm{u}(\mathrm{Z})+\mathrm{K}$ where $\mathrm{K}$ represents consumption of a numeraire competitive good, then the welfare effects of trade can be measured by standard surplus measures.

Figure 2 illustrates the point that there are conflicting effects on welfare. In the figure $z_{0}$ is the pre-trade output of the monopolized good, $\mathrm{p}_{\mathrm{o}}$ is the pre-trade price, and $\mathrm{c}$ is marginal cost. After trade consumption rises to $\mathrm{Z}$ and price falls to $\mathrm{P}_{1}$. But output for domestic consumption falls to $x$, with imports $y$. As the figure shows there is a gain from the "consumption creation" $z_{1}-z_{0}$, but a loss from the "consumption diversion" $z_{0}-x$

\section{FIGURE 2}

There are two special cases in which the welfare effect is clear. First, if transport costs are negligible, the cross-hauling, though pointless, is also costless and the pro-competitive effect insures that there will be gains from trade.

At the other extreme if transport costs are just at the prohibitive level, then decline slightly so that trade takes place, such trade is welfare reducing. This is easily shown as follows. Overall welfare is given by

$$
W=2[u(z)-c z-t y]-F-F^{*}
$$

where we now use $t$ to denote per unit transport costs instead of the iceberg 
notation. The 2 arises because there are two symmetric countries. A slight change in $t$ alters welfare as indicated.

$$
d W / d t=2[(p-c) d z / d t-t d y / d t-y]
$$

Starting at the prohibitive level $p=c+t$ and $y=0$ so sinct $d z / d t=d x / d t+d y / d t,(10)$ reduces to

$$
\mathrm{dW} / \mathrm{dt}=2(\mathrm{p}-\mathrm{c}) \mathrm{dx} / \mathrm{dt}=2 \mathrm{t} \mathrm{dx} / \mathrm{dt}>0
$$

A slight fall in transport costs tends to make $x^{7}$ fall as imports $y$ come in, implying that $\mathrm{dW} / \mathrm{dt}$ is positive. Therefore, a slight fall in $t$ from the prohibitive level would reduce welfare. The intuition runs along the following lines. A decrease in transport costs has three effects. First, costs fall for the current level of imports, which is a gain. Second, consumption rises so, for each extra unit consumed, there is a net gain equal to price minus the marginal cost of imports. Finally, there is a loss due to the replacement of domestic production with high cost imports. For near prohibitive levels of transport costs the first two effects are negligible, leaving only the loss.

\section{Welfare Effects Under Free Entry}

The Cournot duopoly model of Section 2 is quite specific. However, the existence result is robust to a wide variety of generalizations. One important generalization is to the free entry case. Moreover, this case has strong welfare properties. Maintaining the assumptions and notation of Section 2, except that there will now be $n$ firms in each country in equilibrium, the after trade price and foreign market share ny/z, are given by

$$
\begin{aligned}
& p=c \varepsilon_{n}(1+g) / g(2 n \varepsilon-1) \\
& \sigma=(n \varepsilon(g-1)+1) /(1+g)
\end{aligned}
$$


where $\mathrm{n}$ is the number of firms that sets profits equal to zero for each firm i.

We now prove that, under free entry, trade improves welfare. Consider a pre-trade free entry equilibrium. ${ }^{8}$ In the domestic industry each firm maximizes profit so that the following first order condition is satisfied.

$$
x_{i} p^{\prime}+p-c=0
$$

Also, each firm earns zero profit

$$
\pi_{i}=x_{i} p-c x_{i}-F=0
$$

After trade opens price changes, and the direction of price movement determines whether consumer surplus rises or falls, and therefore determines the direction of welfare movement since profits remain at zero by free entry. If price falls, welfare rises. The main step in the argument, then, is that price must fall with the opening of trade.

This is most easily seen by contradiction. From $(14), x_{i}=-(p-c) / p^{\prime}$ so

$$
\begin{aligned}
\mathrm{dx}_{\mathrm{i}} / \mathrm{dp} & =\left(-\mathrm{p}^{\prime}+(\mathrm{p}-\mathrm{c}) \mathrm{p}^{\prime \prime} \mathrm{d} z / \mathrm{dp}\right) /\left(\mathrm{p}^{\prime}\right)^{2} \\
& =-\left(\mathrm{p}^{\prime}+\mathrm{x}_{\mathrm{i}} \mathrm{p}^{\prime \prime}\right) /\left(\mathrm{p}^{\prime}\right)^{2}
\end{aligned}
$$

since $d Z / d p=1 / p^{\prime}$ and $(p-c)=-p^{\prime} x_{i} \cdot$ But (17) is strictly positive by (8) which means that $x_{i}$ must rise if $p$ rises. Also $x_{i}$ must stay constant if $p$ remains constant, so as to satisfy (14). However, profits are now given by

$$
\pi_{i}=(p-c) x_{i}-F+\left(p^{*}-c / g\right) x_{i}^{*}
$$

If price and quantity both rise or remain constant then $(p-c) x_{i}-F$ is nonnegative by $(15)$, and $\left(p^{*}-c / g\right) x_{i}^{*}$ is strictly positive since $p^{*}>c / g$ 
if trade is to take place. Therefore, $\pi_{i}$ must be strictly positive which is a contradiction. Price must fall and welfare must rise.

The structural source of welfare improvement is that firms move down their average cost curves. Although $x_{i}$ falls, $x_{i}+x_{i}{ }_{i}$ must exceed the original production levels and average cost must fall. Profits remain at zero and consumer surplus rises.

\section{Concluding Remarks}

This paper has shown that oligopolistic interaction between firms can cause trade in the absence of any of the usual motivations for trade; neither cost differences nor economies of scale are necessary. The model provides possible explanations for two phenomena not well explained by standard neoclassical trade theory: intra-industry trade and dumping. We refer to such trade as reciprocal dumping. The welfare effects of such trade are interesting. If firms earn positive profits, the opening of trade will increase welfare if transport costs are low. On the other hand, if transport costs are high, opening trade may actually cause welfare to decline because the procompetitive effect is dominated by the increased waste due to transport costs. However, in the free entry Cournot model, opening trade certainly increases welfare.

Reciprocal dumping is much more general than the Cournot model. One direction of generalization (either with or without free entry) is to a generalized conjectural variation model, of which the Cournot model is a special case. The essential element of the conjectural variation model is that each firm has a non-zero expectation concerning the response of other firms to its own output. Letting $\lambda$ denote the expected change in industry 
output as own output changes, so that $\lambda=1$ is the Cournot case, and letting foreign and domestic numbers of firms be $n^{*}$ and $n$ respectively, yields $\sigma=\left(n n^{*} \varepsilon(g-1)+n^{*} \lambda\right) / \lambda\left(n^{*}+n g\right)$ for the case of symmetric linear conjectural variations. This is positive for some range of transport costs. As long as $\lambda>0$, so that firms believe that their behaviour can affect price, the possibility of reciprocal dumping arises. ${ }^{9}$ In general the conjectures need not be symmetric and, for that matter, they need not be linear. An easily developed special case is the Stackelberg leader - follower model in which each firm is, for example, a leader in its home market and a follower abroad. 10

If price is the strategy variable, reciprocal dumping does not arise in the homogeneous product case. However, a slight amount of product differentiation will restore the reciprocal dumping result in which case the intra-industry trade motives described here augment the usual product differentiation motives for intra-industry trade. The important element is just that firms have a segmented markets perception. Given this perception, the possibility of the kind of two-way trade described here is relatively robust.

Finally, we should briefly note another application of our basic analysis. Throughout this paper we have assumed that firms must produce in their home country. Given the assumed equality of production costs, however, firms clearly have an incentive to save transport costs by producing near the market, if they can. But if we allow them to do this, each firm will produce in both countries -- and we will have moved from a model of reciprocal dumping in trade to a model of two-way direct foreign investment. 
*We would like to thank an anonymous referee for very helpful comments.

J. Brander wishes to gratefully acknowledge financial support from a Social Sciences and Humanities Research Council of Canada postdoctoral fellowship.

1. For an exposition of dumping as monopolistic price discrimination see Caves and Jones (1977, pp. 152-154).

2. Two-way trade in similar (but not necessarily identical) products is often referred to as intra-industry trade. Standard references on the importance of intra-industry trade are Balassa (1966) and Grubel and Lloyd (1975). Alternative explanatory models include Krugman (1979) and Lancaster (1980).

3. The "basing point" pricing literature of the 1930s and 1940s was concerned largely with the waste due to cross-hauling in spatial markets. Of special interest is a paper by Smithies (1942) which contains a model of spatial imperfect competition in which crosshauling arises. It is a short step to extend this model to an international setting. Smithies' model differs from ours in that he takes price as the strategy variable, but the basic insight that imperfect competition can cause cross-hauling is central to both.

4. This separation is a very convenient simplification that arises from the assumption of constant marginal cost. It is not essential to the results.

5. Conditions (7) and (8) taken together imply, if they hold globally, that $\pi_{\mathrm{xx}} \pi_{\mathrm{yy}}^{*}-\pi_{\mathrm{xy}} \pi_{\mathrm{yx}}^{*}>0$ globally, which in turn implies that reaction functions cross only once and that they do so such that the equilibrium 
is stable. Allowing violation of (8) and the possibility of multiple equilibria clearly does not upset the result that a two-way trade equilibrium exists. It would, however, complicate welfare analysis in the usual way: one could not be sure which equilibrium would obtain so welfare comparisons of different regimes would usually be ambiguous.

6. Expression (3) implies that $\varepsilon>(1-\sigma)$ while (4) implies that $\varepsilon>\sigma$. Adding these it follows that $\varepsilon>1 / 2$ at equilibrium. It is then clear from (6) that $\sigma<1 / 2$ if $g<1 . \quad(\sigma=1 / 2$ if $g=1$.

7. The fact that $x$ does fall is easily shown by totally differentiating (3) (4) and using (7) and (8).

8. Demonstrating existence and uniqueness of free entry Cournot equilibrium is a general problem to which we have nothing to add. Clearly, there may be "integer" problems in small numbers cases. The interested reader might consult Friedman (1977) and the references cited there.

9. If $\lambda=0$, the first order conditions become $p=c$ for domestic firms and $\mathrm{p}=\mathrm{c} / \mathrm{g}$ for foreigners. Clearly these cannot both hold. There is a corner solution at $\mathrm{p}=\mathrm{c}$ and $\sigma=0$, where the Kuhn-Tucker condition $y(p-c / g)=0$ holds. Ignoring the lower bound at $y=0$ leads to the nonense result that foreign firms would want to produce negative output in the domestic market, which is why the expression for $\sigma$ approaches $-\infty$ as $\lambda$ approaches 0 . $\sigma$ should of course be bounded below at 0 .

10. Brander and Spencer (1981) examine the implications for tariff policy of a market structure in which the foreign firm is an entry-deterring or potentially stackelberg leader in both markets. 


\section{References}

Balassa, Bela, 1966, Tariff reductions and trade in manufactures, American Economic Review 56, 466-73

Brander, James A., 1981, Intra-industry trade in identical commodities, Journal of International Economics $11,1-14$

Brander, James A. and Barbara J. Spencer, 1981, Tariffs and the extraction of foreign monopoly rents under potential entry, Canadian Journal of Economics $14,371-89$

Caves, Richard and Ronald W. Jones, 1977, World trade and payments, 2nd ed. (Little, Brown and Company, Boston)

Ethier, Wilfred, 1982, Dumping, Journal of Political Economy 90, 487-506 Friedman, James w., 1977, Oligopoly and the theory of games (North-Holland, Amsterdam)

Grubel, Herbert and Peter Lloyd, 1975, Intra-industry trade (Wiley, New York)

Helpman, Elhanan, 1982, Increasing returns, imperfect markets, and trade theory, Discussion Paper, Tel Aviv University

Krugman, Paul, 1979, Increasing returns, monopolistic competition and international trade, Journal of International Economics 9, 469-479 Lancaster, Kelvin, 1980, Intra-industry trade under perfect monopolistic competition, Journal of International Economics 10, 151-175

Seade, Jesus, 1980, On the effects of entry, Econometrica 48, 479-89 Smithies, Arthur, 1942, Aspects of the basing-point system, American Economic Review 32, 705-26 


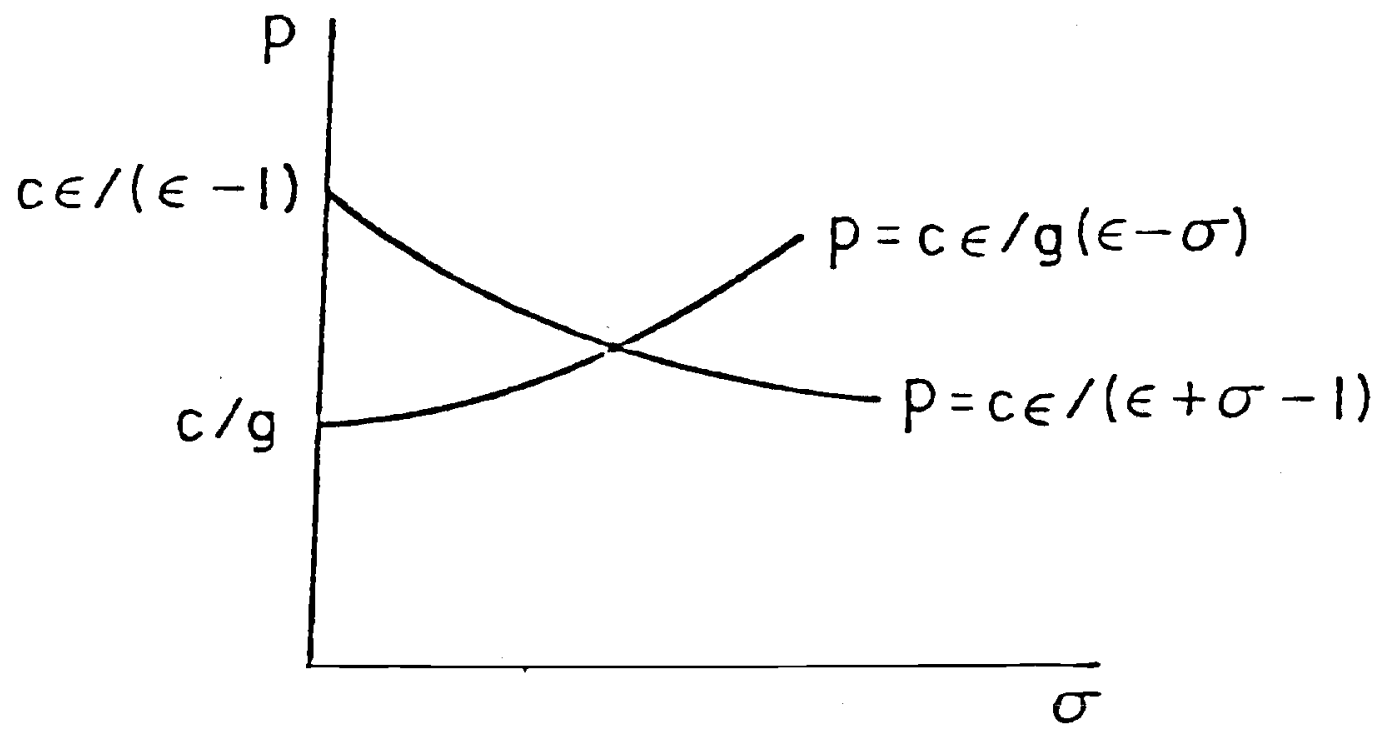

Figure 1 


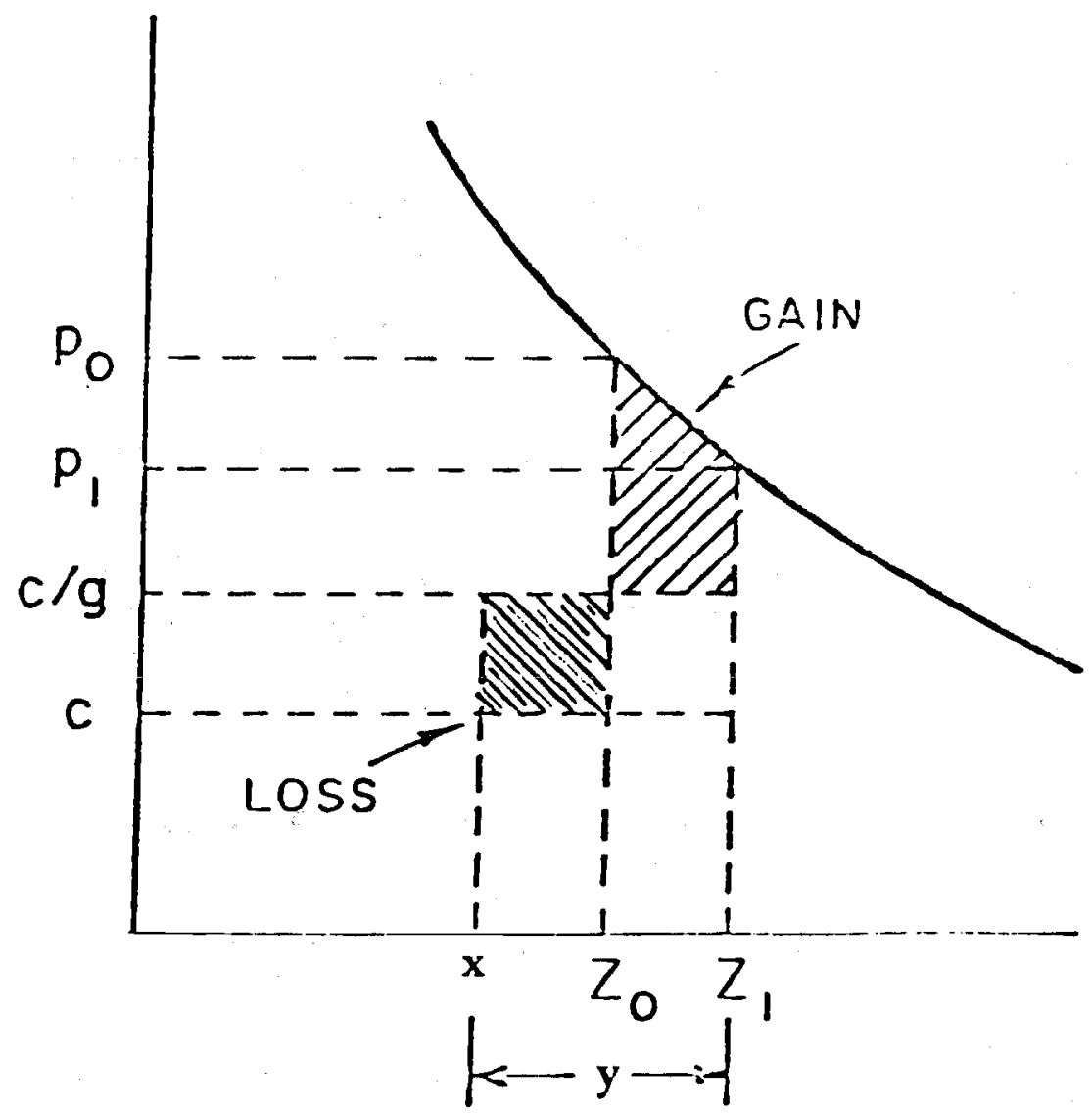

Figure 2 